\title{
Student Academic Mentoring (SAM): peer support and undergraduate study
}

\section{Gillian Pye}

Edge Hill University, UK

\section{Susan Williams}

Edge Hill University, UK

\section{Linda Dunne}

Edge Hill University, UK

\begin{abstract}
University mentoring programmes are increasingly being used to assist and support undergraduate students. Mentoring can take various forms, it may be one to one; face to face; small group or online. It may be between student peers or students and tutors. There is no homogeneous approach and differing mentoring schemes emerge from particular contexts. The purpose of the case study research presented in this paper was to critically evaluate an academic mentoring project that involved year 2 undergraduate students mentoring year 1 students on an education-based degree. The tripartite structural approach involved individual, small group and in-class mentoring. Research data was collected via semi-structured interviews, focus groups, questionnaires and student, mentor and tutor evaluations. The main themes that emerged, following analysis, relate to academic support, socialisation and attrition. Findings also highlight the benefits of a mentoring project that took various forms rather than a singular approach. Scaffolded, collaborative learning, in co-caring communities of practice, appeared to positively affect year 1 student confidence, self-efficacy and motivation. Other benefits included easing the transition from school to university and engendering a sense of belonging.
\end{abstract}

Keywords: peer mentoring; academic support; socialisation; communities of practice. 


\section{Introduction}

Mentoring and coaching has become a growing phenomenon across the world. The UK Government has invested in mentoring in education, health and prison services and this expenditure suggests that it is positive in terms of the results it produces. Mentoring programmes are assumed to be of value to students (Crisp and Cruz, 2009), although the specifics of how, and what structures, features or characteristics can be successfully replicated to benefit others, seem to be less well defined. The aim of the case study research presented in this paper was to evaluate a pilot Student Academic Mentoring (SAM) project that involved two year 2 undergraduate students each mentoring five year 1 students from a cohort of 25 on an undergraduate degree in Teaching, Learning and Mentoring (TLM) at a post-1992 university in the northwest of England. We have worked as lecturers, researchers and personal tutors on the TLM degree for a number of years. Our research was conducted over the course of an academic year and addressed the question 'what are the benefits and challenges of undergraduate student academic peer mentoring?'

The TLM degree originated as part of the UK's Higher Education Widening Participation (DBIS, 2013) policy agenda and offers pathways into teaching or to employment working with children and young people. There is a greater tendency for working-class students in the UK to go to post-1992 universities, which tend to have more open access, encourage diverse applicants and increase chances of belonging in an academic culture (Reay et al., 2010). The impetus for the Student Academic Mentoring (SAM) project initially arose from an institutional-wide focus on student induction and retention. In a climate of increased competition and league tables (where further and higher education establishments are judged and ranked on student attainment, satisfaction and degree completion) various strategies, such as student mentoring, are being implemented and evaluated. As Duckworth and Maxwell (2015) indicate, mentoring, like other care-driven aspects of education, is now in danger of being co-opted into a neoliberal regime characterised by judgements driven by a standards agenda. One of the main aims and purposes of the SAM project, in addition to addressing issues relating to student engagement, retention and attrition, was to veer away from judgements or the reinforcement of particular ways of being, and to primarily address fears that new students may have relating to the process of 
academic study through the creation of a co-caring, supportive learning community of practice.

\section{Mentoring}

A generic definition of academic mentoring does not exist and much of the data generated from studies about mentoring is situational in nature and specifically relates to individual settings (e.g. Fox et al., 2010; Mee Lee and Bush, 2003; Leidenfrost et al., 2011). Given the contextualised nature of mentoring activity, definitions which do exist are equally diverse in nature (Terrion and Leonard, 2007; Darwin and Palmer, 2009). Jacobi (1991, p. 505) laments the lack of an accepted definition and muses that these activities have little in common to define them other than a 'sincere desire to help students succeed'; although Loots (2009, p.214) counters that there is no 'meta-paradigm' into which mentoring fits and the diversity of mentoring activity should be celebrated. For the purpose of our case study, drawing on experience, wider definitions and common themes found in the literature, an academic mentor is understood to be a more experienced individual willing to share knowledge, skills and experiences with someone less experienced in a relationship of mutual trust, predicated on care (Pye, 2013).

Kerry and Mayes (1995) offer three basic conceptual models of mentoring; the apprenticeship model (learning by emulating a skilled practitioner); the competency model (undergoing practical training) and the reflective practitioner model (taking an active role in demonstrating and practicing skills). Within the context of higher education, a variety of approaches utilising aspects of these three models have been adopted, including dyadic mentoring and peer-tutoring (Garvey et al., 2009; Mee Lee and Bush 2003; Smailes and Gannon-Leary, 2011; Smith, 2013). These are variously referred to as PAL (Peer Assisted Learning), PASS (Peer Assisted Study Sessions), SPAM (Student Peer Assisted Mentoring) and SI (Supplemental Instruction). One of the three approaches used in SAM was similar to Darwin and Palmer's (2009) mentoring circles, where small group discussion was facilitated by a mentor, and student experiences and ideas were shared to co-create learning.

More formalised models of mentoring in higher education serve a number of purposes, such as student retention, readiness for university, and academic support. These models 
are often characterised by mentors and mentees being carefully matched in terms of dispositions and personality and although the power dynamics involved in this kind of relationship can be problematic (Christie, 2014; Colvin and Ashman, 2010), this process does appear to increase mentee motivation, engagement and participation (Saich, 2008). Even more prevalent in formalised mentoring is the matching of students and mentors in terms of academic modules studied, whereby mentors are more able to offer support in work which they have already undertaken and have an understanding of the assessment requirements (Saich, 2008). Mentors have been through the process that their mentees are now participating in, and this appears to lead to greater commitment from mentor and mentee (Mee Lee and Bush, 2003).

The SAM case study was formalised to some extent, but participation as a mentor and mentee was purely voluntary. When mentoring is voluntary, participation is likely to increase; when it is made compulsory or integrated into formal academic study and assessment, difficulties may arise in terms of time and student choice of mentor (Mee Lee and Bush, 2003). The voluntary mentor-mentee relationship is critical (Garvey et al., 2009; Weinberg and Lankau, 2010) and there is a need to build rapport, trust, collaboration and openness in such relationships for them to be productive and impact upon learning (Megginson and Clutterbuck, 2005). Mentors may benefit from the experience of participating in mentoring activities as much as a mentee and may experience reinforced self-esteem and confidence; exhibit a feel-good factor from being able to help another student (something that they may have appreciated themselves in their own studies); deepen their own knowledge by revisiting topics already studied; develop their interpersonal skills and increase their own employability; although there are no widely substantiated claims that mentors benefit academically from the process (Kirkham and Ringelstein, 2008; Mladenovic, 2012; Page and Hanna, 2008; Smith, 2013). When mentoring is structured in a way that is beneficial it may have positive effects on undergraduate socialisation, confidence, self-esteem, perseverance, academic attainment and completion of studies (Carnell et al., 2006; Saich, 2008; Crisp and Cruz, 2009; Smith, 2013). Such support, when resulting in collegiate working mentor-mentee relationships, can ease the transition from school to university life, increase socialisation and engender a sense of belonging (Cook and Rushton, 2009; Loots, 2009; Thomas, 2012; Collings et al., 2014). 


\section{The SAM project}

Lave and Wenger (1991) place learning in social relationships and in situations of coparticipation where social engagements provide the context and structure for learning to take place. Learning involves participation in a community of practice that provides an encompassing process of being active participants in 'the practices of social communities and constructing identities in relation to these communities' (Wenger, 1999, p.4). The SAM project was underpinned by this notion of learner communities of practice and one of the aims was to demystify learning in higher education through peer interaction and support. The nature of SAM was in many ways aligned with the nurturing and caring aspects of Anderson and Shannon's (1988) model of mentoring that encompasses reflective practice.

Prior to the project, a job description outlining the mentor role and person specification was issued to year 2 students inviting applications from those wishing to act as academic mentors to year 1 students. From the six applicants, two successful candidates were chosen because of their passion, commitment, caring disposition and desire to offer support and guidance to others. Interestingly, the two students had experienced mentoring themselves and both recognised and valued the benefits. The two student academic mentors followed a training and induction programme before the mentoring process began, which focussed on communication skills, support strategies, building rapport, trust and an ethic of care (Noddings, 1996). The mentors were then each matched as closely as possible in relation to personality, background, aptitude and so on, with 5 year 1 students who had agreed to be mentored at the start of a new academic year. The programme leader drew on existing knowledge of the year 2 mentors, and on information gained at interview and student profiling of year 1 students to match the mentors with their mentees. It is worth noting that all students were of White British ethnicity, from a working-class background and most of them had part-time employment in order to help finance their undergraduate studies.

In attempting to foster a supportive learning culture (Bruffee, 1984), the year 2 mentors operated in a variety of ways to support year 1 students. The tripartite structural approach of SAM involved individual, small group and in-class mentoring. Individual mentoring involved one-to-one contact, with mentors voluntarily engaging with their mentees, both face to face and electronically, to answer questions relating to, amongst other things, academic support, assignment writing and preparation for school-based placement. 
Mentors were available for small group meetings at the request of their mentees. These group meetings could be regarded as study groups, facilitated and led by the mentor. Inclass mentoring involved the mentors participating in tutor-facilitated academic support sessions designed to scaffold the academic writing process for year 1 groups, with the tutor and the academic mentor working jointly on the writing process in a co-construction of learning. This aspect of SAM enabled the two mentors to interact with a greater number of students, aside from those having an assigned mentor, and become 'recognisable' to the first year student cohort as a whole. This interaction and visibility was encouraged as it was felt that it would consolidate trust, rapport and enable all year 1 students to witness, and to some extent experience, the mentor role.

\section{Research approach}

The ontological and epistemological position of this paper is an interpretivist one, within a qualitative paradigm. A value of qualitative interpretivist research is that it is set within naturalistic and holistic confines and as a result can offer a variety of interpretations and explanations utilising naturally occurring data (McEwan-Adkins and McEwan 2003; Taber, 2013). Punch (2006, p.49) maintains that qualitative studies can often be an 'unfolding study' and a case study approach was an appropriate way to illuminate the characteristics of the mentoring project. Bassey $(1999$, p.65) defines case study research as:

An empirical enquiry into interesting aspects of educational activity...to inform judgements or decisions....with data...to explore the significant features for the work, create plausible interpretations...to test for trustworthiness and construct an argument or story.

A case study approach allowed for an in-depth exploration of the SAM project over a sustained period of time and an evaluation of its impact from within its natural setting (Burton and Bartlett, 2005).

All those who participated in SAM, (students and tutors) were informed of the projects aims and purposes. Ethical permission to conduct the research was obtained from the university and those involved in data collection signed consent forms and understood they could withdraw from the project at any time. 
A pre and post-mentoring anonymised questionnaire, designed to ascertain feelings and perceptions (Denscombe, 2010) was given to all students within the year 1 cohort asking about their attitudes towards, and experiences of, academic study at the start and end of the project. The ten mentored students, the two mentors and three module tutors were interviewed towards the end of the academic year in order to gain their perspectives. Interviews were regarded as conversations with a purpose (Denscombe, 2010) and they provided an opportunity to explore in some depth the complexities of the project. Openended questions allowed for personal accounts and adaptations of experiences and access to the 'main road to multiple realities' (Stake, 1995, p.64). The research sample size was relatively small, yet setting out to understand students' attitudes and perceptions of SAM, allowed us, as researchers, to 'mine the richness and depth' (Silverman, 2013, p.66) of this particular unfolding case study story.

Follow-up focus groups were conducted that allowed the ten mentored students an arena for feedback that was supportive and non-threatening (Menter et al., 2011). Focus groups involve a blend of observation and interviewing (Morgan, 1997), facilitate group discussion and put multiple perspectives on the table. Kamberelis and Dimitriadis (2005) suggest that they allow researchers to explore the nature and effects of ongoing social discourse in ways that are not possible through individual interviews and observations. The 45-minute focus group sessions were held in a convivial setting and were audio-recorded and later transcribed. They were conducted by the mentors, based on a desire to acknowledge the power dynamic between researcher(s) and students. We felt that the students' would show greater openness in discussing with the mentors rather than with the tutor/research team and may have helped to reduce researcher bias.

Observation, as a method of collecting rich qualitative data in naturalistic settings, reveals information not seen in interviews and focus groups. Behaviours, interactions and activities were observed where students and mentors were operating in their 'real' environment (Silverman, 2013), that is, in the classroom. Participant observation gave access to, and a greater awareness of, the more salient issues which assisted in analysis and subsequent interpretation of analysed data (Menter et al., 2011). Analysis is the researcher's equivalent of alchemy; the elusive process by which raw data is turned into 'nuggets of pure gold' (Briggs and Coleman, 2007, p.68). The first stage of analysis was 'data management and data reduction' (Elton-Chalcraft et al., 2008, p.132) and the creation of an 'audit trail', whereby steps were re-traced through the whole process. Content analysis 
involved coding and cross referencing of the data sets (Gibbs, 2008), with the aid of thematic mind maps to elicit emergent themes which are discussed in the following section.

\section{Findings}

As indicated earlier, a particular and possibly unique feature of the SAM project was the tripartite structural approach that comprised of individual mentoring, small group mentoring akin to mentoring circles (Darwin and Palmer, 2009), and also mentoring of the same small groups in tutor-led academic support sessions that involved the whole cohort of year 1 students and in-class support. The three approaches appeared to work very well and were evaluated positively. The themes that emerged from analysis relate to academic support, socialisation and attrition.

\section{Academic support}

From responses to the pre-mentoring questionnaire, it was clear that year 1 students who had opted to be mentored had felt anxious or concerned about academic writing at the start of term; did not feel particularly confident about approaching academic study generally and needed extra re-assurance that they 'were doing things right'. Students signified that they wanted assurance that the academic support being offered by mentors was of a similar quality as that offered by a tutor.

Some peer-mentoring programmes that have focused on a dyadic model of mentoring have reported success in raising attainment of students (Kirkham and Ringelstein, 2008; Loots, 2009; Fox et al., 2010; Leidenfrost et al., 2011). In focus group discussions, students who had had regular one to one mentoring responded positively when discussing academic support, asserting that they felt much more assured and confident about planning, writing and referencing. The mentored students encapsulated their feelings towards the three approaches by stating:

I liked the way it was set up ... you could go on your own but the group sessions were really useful too. 
I would feel better about approaching the mentor if it was part of a small group session.

I'd like the mentors to be able to spend more time with small groups in the academic support sessions.

When discussing the student benefits associated with taking part in the one to one, as well as the small and wider group mentoring, students appreciated talking about assignments, assessment and study skills.

It was great to hear mentors talk about the assessment they had done before.

They helped to explain the referencing system to me and improved the quality of my work by asking me questions about it.

They could recommend certain books or journals for certain lectures or topics and enhanced study skills.

All mentored students unanimously identified the whole-class academic support sessions, where collaborative working between tutors, mentors and students occurred, as being a particularly helpful support mechanism for reflection and sharing of ideas. They appreciated the opportunity to work on their assignment drafts in academic communities of practice (Lave and Wenger, 1991) that were akin to mentoring circles (Darwin and Palmer, 2009). Where mentored students were encouraged to work collaboratively in a wider group, under the guidance of the mentor, positive effects seemed to follow, reflecting other research around mentoring, collaboration and feedback (Elder, 2012; Hattie, 2012). Within tutor-led academic support sessions mentors and mentees worked together in small groups, sharing and exploring questions and ideas collectively. Tutors commented that a more systematic and analytical approach to writing had developed:

Students have developed strengths in how to tackle a particular question...they now have a sense of which direction to go in approaching a question.

l've noticed a huge difference...their level of engagement and their confidence levels seems to have gone up considerably. 
Collaborative learning was valued as a way of working and a learning culture (Bruffee, 1984) was beginning to develop. The domain of this community was the classroom and learning conversations were centred on what the students were writing and why they were writing in a particular way. During observations, it was noted that students asked questions of themselves and their writing, demonstrating a developing understanding of the academic process. For example, 'I've linked two authors like this...would this be accurate?' and 'can I reference these authors to talk about this...?' The nature of these learning conversations became more reflective via gentle but in-depth questioning by the mentors when supporting and scaffolding the learning of their mentees. This was corroborated by a tutor interview where it was remarked that:

There were lots of really interesting conversations going on...the mentors were really challenging the students.

Mentors and students appeared to become more resilient in their approach to more challenging aspects of study and less reliant solely on tutors for continuous support and guidance (Kirkham and Ringelstein, 2008; Smith, 2013).

Interestingly, the students who had not opted to participate in mentoring had arranged themselves into self-selecting, friendship-based support groups, which seemed to provide the same support mechanism as offered by the mentors, suggesting that students benefit from a multitude of mentors. This particular group of students were more academically able (based on UCAS entry point scores) and possibly more confident about academic writing. The support and care they offered to each other mirrored the way the mentors supported their mentees, in a similar way that mentoring circles have seen a move away from the traditional dyadic model of mentoring to a more collaborative approach (Smith, 2013). This collaboration, and the ethos of the classroom, signalled, for us, a 'lack of isolation felt by students, an increase in confidence, greater knowledge acquisition and a demystification of academia' (Darwin and Palmer, 2009, p.127).

Being able to talk about school professional placement, and how the degree relates to schooling and education, was a real positive for the mentees and appeared to allay anxieties. At the earliest point in an undergraduate career the most useful support for a student can come from someone who has experienced what they are experiencing now 
(Saich, 2008) and this appeared to be the case during the SAM project. Several mentees commented that talking through the approaches to lesson planning was extremely valuable as preparation for school placement.

A mentor's own learning improves as they learn to teach others, thus developing key employability skills for the future (Thomas, 2012). The mentors derived unforeseen benefits from the process of mentoring, stating:

I have gained more confidence in completing my own assignments after doing this...I have learned a lot about how to offer others help and support.

The mentor programme has helped confirm for me my future career direction...mentoring is what I want to do.

In terms of the kinds of teaching and learning related activities undertaken, as with other studies, the mentors felt mostly confident in supporting in areas that they had previously studied themselves (Saich, 2008; Mee Lee and Bush, 2003), although there were initial fears stemming from the unexpected and unfamiliar:

I was apprehensive at first because I didn't know what to expect....after the first few sessions I felt I knew what I was offering in terms of support.

At first it was a daunting prospect to be trusted to work with other students...I wasn't sure I knew what to do...but when I started I knew I had the skills to do this.

Tutor interviews substantiated the benefits of the mentoring role: when asked if they felt it had an impact on the mentors they commented:

Definitely - I think particularly for one of them who wants to follow mentoring as a career. It has enabled her to grow enormously. It has built her confidence.... and to believe in her own abilities... and helped in realising she really wants to do this.

I noticed a level of professionalism has grown: they [mentors] were coming in with resources after the first week, with suggestions, or had been and looked at something. Alex said "you know they got back to me the same day" so there was a 
level of engagement between them. They responded like you would with a class, responding to peoples' needs. So I think in terms of growth for the second year mentors...certainly. What I saw was a degree of professionalism growing.

\section{Socialisation and attrition}

The SAM project manifested additional benefits in that students suggested that they had become more socialised to the university and to their course of study. Mentoring schemes have been adopted as a means of preventing student attrition (Saich, 2008; Smith, 2013) and whilst SAM did not have this singularly explicit aim, there seems to be some evidence that it did encourage students to stay on board with their studies. A student in perceived danger of withdrawing from the degree due to mental health difficulties seemed to have renewed commitment to study in response to the ethos and spirit of the project. Tutors commented that:

One student in particular who was quite worrying, in that he could have dropped out...I think the mentoring process with its ethos...that made that group of students who were befriending him, brought him on and encouraged him to write his assignment and to be more focussed. So I think this student, who we could have potentially lost, stayed. The students themselves were taking on this mentoring culture, and perhaps gathered him in and encouraged and motivated him....whereas, maybe you know...perhaps tutors and lecturers were a little too remote?

I think the help they got, helped them to bond a little better...because there was a potential divide in that group and strangely enough the mentors helped create a bond...in the academic writing session there was lots of dialogue drawing the two groups together.

Students commented that they felt comfortable in approaching the mentors if they needed help and mentors reported on the positive impact of the matching of the students to mentors. A mentor commented that:

I got on with the students and this made it easier to work with them on the academic stuff. 
This was further exemplified by a tutor comment:

I think there was a deep level of trust developing there between the students and mentors.

Socialisation appeared to be predicated on mutual trust:

There was trust and mutual respect between the students and mentors and the students certainly were taking on board what the mentors were saying to them.

Bernier et al. (2005) suggest that the greater correlation in deliberately attempting to match mentor and students, the greater the outcome of success. Along with openness and the development of friendships, came the narrow line between friendship and what may be termed 'professionalism', and some students questioned the nature of the mentor-student relationship in terms of over-familiarity. Some students, not participating in the one to one aspect of the project, felt that some individuals took over and dominated the mentor's time and, as one commented: 'it seems like the mentors worked with small groups and became friends with them'.

Mentees appeared to benefit from exposure to mentoring in academic as well psychosocial ways (Mladonevic, 2012) and knowledge acquisition appeared to accelerate by opportunities to discuss lecture and assessment work with others, which increased confidence to tackle other aspects of study. The psychosocial benefits to the students may have engendered a sense of belonging to the institution and aided transition from school to university (Thomas, 2012), although this was not an aspect explored in great depth. The mentors and mentees did signify that they felt they 'belonged' to the university and this sense of belonging appeared to have been nurtured by socialisation, care and dialogue. In relation to mentees, tutors remarked that:

I think the transition into higher education has become a little smoother because they have had someone they can talk to about university life as well as academic study. 
I think the Year 1 group is acting as a more cohesive group than the previous group of students the year before at the same stage. There was a real bond developing within this group as a result of the way in which they were working. There was good, healthy dialogue.

\section{Discussion}

Our research set out to address the question 'what are the benefits and challenges of undergraduate student academic mentoring?' A number of significant benefits emerged from SAM that included an apparent strengthening of student engagement with university life, sense of belonging to the institution and the fostering of a community of practice. SAM formed a key role within an intervention strategy, feeding into student academic support sessions, as well as the students drawing on the skills of the mentors on a one to one or small group basis. By collaborating in academic support sessions and by participating in one to one mentoring, students' confidence levels appeared to increase and their self-efficacy was enhanced by their involvement in the project. Those students participating more fully in the one to one mentoring would seem to have benefitted from the individualised guidance and support on aspects of writing, but what also appears to have been revealed is the mutual benefit for all students within the wider cohort. Students have been exposed to learning conversations between peers and mentors adding some intellectual richness to student learning opportunities (O'Shea and Vincent, 2011; Elder, 2012; Smith, 2013).

Socialisation of students has been a contributory feature to the success of SAM and the collaborative nature of much of the mentoring activity allowed both socialisation and academic activities to exist simultaneously (Smith, 2013). Although student retention was not an overriding reason for investigation at the beginning of the project, there are signs that SAM has had an impact, not necessarily directly through the mentoring activity, but through the peer-supported group of students, who mirrored the work of the mentors in their own friendship-based study group. Matching students as far as possible, alongside the voluntary nature of the project, did appear to foster a more productive and collegiate working relationship and is more likely to help to retain students who may otherwise have given up on their studies (Weinberg and Lankau, 2010). 
Universities often state their reasons for engaging with mentoring are to recruit and retain students on their degree programmes (Saich, 2008), yet few institutions appear to use the prevalence of a mentoring scheme as a marketing tool, or a means of highlighting peer support to prospective students (Cook and Rushton, 2009). The mentors signified that they wished they had a mentor in their first year to support them and this suggests that the relative success of SAM ought to be included in marketing materials that focus on the recruitment of students who may be reticent or fearful about studying at university. The perception of the students themselves is that they believe participating in the mentoring process has developed them as learners. This has made them more likely to act as mentors themselves in the future and has, for some, consolidated career choices.

One challenge that emerged was largely related to relationships and mentor - mentee relationship boundaries. It is perhaps inevitable that mentors and mentees may become emotionally attached, given the nature of the relationship (Collings et al., 2014). 'Mentor' as 'friend' is fine as a mentor-mentee outcome, but the focus of mentoring may become distorted by 'becoming friends' from the start (Christie, 2014). As Zier-Vogel and Barry (2013) suggest, the ethics of the mentoring relationship is crucial and they cannot be left to chance. Issues that arose, such as the blurred boundaries between what may be termed 'professionalism' and friendship, will be addressed in future mentor training via scenarios and role play.

That students signified they wanted assurance that the academic support being offered by mentors was of the same quality as that offered by a tutor suggested that the mentor role needs to be more strongly clarified for the whole student cohort. This has implications for the training of mentors in that they perhaps need to feel secure in their own subject knowledge and have the cognitive scaffolding (Millar, 2002) and support strategies to give that guidance to other students (Zier-Vogel and Barry, 2013). The integrity of the mentor's position in supporting other students cannot be compromised, and the trust and openness that can develop within these relationships is complimented by willingness and a capacity to genuinely support and guide students rather than completing work on their behalf. Hence, students and mentors need a shared understanding that mentoring is not a substitute for tutor support and that the nature of the student-mentor relationship is different to a student-tutor one. 


\section{Conclusion}

Evaluative findings from the SAM case study contribute to the work already undertaken in the area of creating learning communities, or communities of practice (Lave and Wenger, 1991), where students can explore and collaborate on their work and share experiences within that practice (Tinto, 1997; Cook and Rushton, 2009; Darwin and Palmer, 2009; Smailes and Gannon-Leary, 2011; Smith, 2013). Our research has provided an insight into the ways in which students' motivation, through cooperation and co-construction, can foster a collegiate commitment to a programme of study that is particularly valuable for students from working class backgrounds who may, for whatever reason, feel that they do not fit in or 'belong' at university (Reay et al., 2010).

The tripartite mentoring model, which comprised of individual, small group and also mentoring of the same small groups in tutor-led in-class academic support sessions, was more beneficial, overall, than a singular model. The in-class academic support demonstrates some uniqueness in SAM's approach and potentially changes the nature of future tutor-led or Learning Services academic sessions at the university.

SAM has been welcomed by students and mentors who expressed a desire for the project to continue and a willingness to participate in the project, as mentors, in future years. In the meantime, we will continue to implement and research SAM as it develops and evolves. The intention is to widen and extend the tripartite academic mentoring model and to further incorporate a mentoring circles model (Darwin and Palmer, 2009) for finding solutions to challenges that may arise during student professional placement experience in schools. There is much possibility for development (for example, incorporating SAM into the undergraduate curriculum) and for further research on aspects of the project. At the time of writing, in-depth case study research is being undertaken exploring the learning experiences of two students, one of whom was considering leaving university prior to his involvement with SAM. Further research is also being planned on the quantitative impact of SAM and the raising in attainment of academic scores, via a longitudinal study that may establish a relationship between peer mentoring and academic success. 


\section{References}

Anderson, E. and Shannon, A. (1988) 'Towards a conceptualization of mentoring', Journal of Teacher Education, 39(1), pp. 38-42. http://dx.doi.org/10.1177/002248718803900109

Bassey, M. (1999) Case study research in educational settings. Buckingham: Open University Press.

Bernier, A., Larose, S. and Soucy, N. (2005) 'Academic mentoring in college: the interactive role of student's and mentor's dispositions', Research in Higher Education, 46(1), pp. 29-51. http://dx.doi.org/10.1007/s11162-004-6288-5

Briggs, A. and Coleman, M. (eds.) (2007) Research methods in educational leadership and management. $2^{\text {nd }}$ edn. London: Sage Publications.

Bruffee K. A. (1984) 'Collaborative learning and the "conversation of mankind", College English, 46(7), pp. 635-652.

Burton, D. and Bartlett, S. (2005) Practitioner research for teachers. London: Sage Publications.

Carnell, E., MacDonald, J. and Askew, S. (2006) Coaching and mentoring in higher education: a learning-centred approach. London: Institute of Education.

Christie, H. (2014) 'Peer mentoring in higher education: issues of power and control', Teaching in Higher Education, 19(8), pp. 955-965. http://dx.doi.org/10.1080/13562517.2014.934355

Collings, R., Swanson, V. and Watkins, R. (2014) 'The impact of peer mentoring on levels of student wellbeing, integration and retention: a controlled comparative evaluation of residential students in UK higher education', Higher Education, 68(6), pp. 927942. http://dx.doi.org/10.1007/s10734-014-9752-y 
Colvin, J. W. and Ashman, M. (2010) 'Roles, risks, and benefits of peer mentoring relationships in higher education', Mentoring and Tutoring: Partnership in Learning, 18(2), pp. 121-134. http://dx.doi.org/10.1080/13611261003678879

Cook, A. and Rushton, B. (2009) How to recruit and retain higher education students: a handbook of good practice. Oxon: Routledge.

Crisp, G. and Cruz, I. (2009) 'Mentoring college students: a critical review of the literature between 1990 and 2007', Research in Higher Education, 50(6), pp. 525-545. http://dx.doi.org/10.1007/s11162-009-9130-2

Darwin, A. and Palmer, E. (2009) 'Mentoring circles in higher education', Higher Education Research and Development, 28(2), pp. 125-136. http://dx.doi.org/10.1080/07294360902725017

Denscombe, M. (2010) The good research guide: for small-scale social research projects. Berkshire: Open University Press.

Department for Business, Innovation and Skills (DBIS) (2013) Widening Participation in Higher Education. Available at:

https://www.gov.uk/government/collections/widening-participation-in-highereducation (Accessed: 19 April 2016).

Duckworth, V. and Maxwell, B. (2015) 'Extending the mentor role in initial teacher education: embracing social justice', International Journal of Mentoring and Coaching in Education, 4(1), pp. 4-20. http://dx.doi.org/10.1108/lJMCE-08-2014$\underline{0032}$

Elder, Z. (2012) Full on learning: involve me and l'll understand. Carmarthen: Crown House Publishing.

Elton-Chalcraft, S., Hansen, A. and Twistleton, S. (2008) Doing classroom research: a step-by-step guide for student teachers. Berkshire: Open University Press. 
Fox, A., Stevenson, L., Connelly, P., Duff, A. and Dunlop, A. (2010) 'Peer-mentoring undergraduate accounting students: the influence on approaches to learning and academic performance', Active Learning in Higher Education, 11(2), pp.145-156. http://dx.doi.org/10.1177/1469787410365650

Garvey, B., Stokes, P. and Megginson, D. (2009) Coaching and mentoring: theory and practice. London: Sage Publications.

Gibbs, G. (2008) Analysing qualitative data. London: Sage.

Hattie, J. (2012) Visible learning for teachers: maximising impact for learning. Oxon: Routledge.

Jacobi, M. (1991) 'Mentoring and undergraduate academic success: a literature review'. Review of Educational Research, 61(4), pp. 503-532. http://dx.doi.org/10.3102/00346543061004505

Kamberelis, G. and Dimitriadis, G. (2005) 'Focus groups: strategic articulations of pedagogy, politics and inquiry', in Denzin N. and Lincoln Y. (eds.) The sage handbook of qualitative research. 3rd edn. London: Sage Publications, pp. 887-914.

Kerry, T. and Mayes, A. (eds.) (1995) Issues in mentoring. London: Routledge.

Kirkham, R. and Ringelstein, D. (2008) 'Student peer assisted mentoring (SPAM): a conceptual framework', e-Journal of Business Education and Scholarship of Teaching, 2(2), pp. 39-49.

Lave, J. and Wenger, E. (1991) Situated learning: legitimate peripheral participation. Cambridge: Cambridge University Press.

Leidenfrost, B., Strassnig, B., Schabmann, A., Speil, C. and Carbon, C. (2011) 'Peer mentoring styles and their contribution to academic success among mentees: a person-oriented study in higher education', Mentoring and Tutoring: Partnership in Learning, 19(3), pp. 347-364. http://dx.doi.org/10.1080/13611267.2011.597122 
Loots, A. (2009) 'Student involvement and retention in higher education: the case for academic peer mentoring programmes for first years', Education as Change, 13(1), pp. 211-235. http://dx.doi.org/10.1080/16823200902945077

McEwan-Adkins, E. and McEwan, P. (2003) Making sense of research: what's good, what's not and how to tell the difference. London: Sage Publications.

Mee Lee, L. and Bush, T. (2003) 'Student mentoring in higher education: Hong Kong Baptist University', Mentoring and Tutoring: Partnership in Learning, 11(3), pp. 263271. http://dx.doi.org/10.1080/1361126032000138319

Megginson, D. and Clutterbuck, D. (2005) Techniques for coaching and mentoring. Oxford: Butterworth-Heinemann.

Menter, I., Elliot, D., Hulme, M., Lewin, J. and Lowden, K. (2011) A guide to practitioner research in education. London: Sage Publications.

Millar, A. (2002) Mentoring students and young people: a handbook of effective practice. London: Kogan-Page Limited.

Mladonevic, M. (2012) Mentoring in higher education, Virginia Polytechnic Institute and State University, Fall issue. Available at:

http://milosnmladenovic.info/Professor\%20Milos\%20Mladenovic\%20publications/M entoring\%20in\%20Higher\%20Education\%20-\%20Mladenovic.pdf (Accessed: 19 April 2016).

Morgan, D. (1997) Focus groups as qualitative research. 2nd edn. London: Sage Publications.

Noddings, N. (1996) 'The Cared-for', in Gordon, S., Benner, P. and Noddings, N. (eds). Caregiving: readings in knowledge, practice, ethics, and politics. Philadelphia: University of Pennsylvania Press, pp. 21-39. 
O'Shea, S. and Vincent, M. (2011) 'Uni-start: a peer-led orientation activity for the early and timely engagement of commencing university students', The Journal of Continuing Higher Education, 59(3), pp. 152-160. http://dx.doi.org/10.1080/07377363.2011.614885

Page, D. and Hanna, D. (2008) 'Peer mentoring: the students' perspective', Psychology Learning and Teaching, 7(2), pp. 34-37. http://dx.doi.org/10.2304/plat.2008.7.2.34

Punch, K. (2006) Developing effective research proposals. $2^{\text {nd }}$ edn. London: Sage Publications.

Pye, G. (2013) Student academic mentoring. Unpublished thesis. Edge Hill University.

Reay, D., Crozier, G. and Clayton, J. (2010) 'Fitting in' or 'standing out': working-class students in UK higher education', British Educational Research Journal, 36(1), pp. 107-124. http://dx.doi.org/10.1080/01411920902878925

Saich, G. (2008) 'Explicit first year support through university student mentoring' International Journal of Learning, 15(10), pp. 1-10.

Silverman, D. (2013) Doing qualitative research: a practical handbook. $4^{\text {th }}$ edn. London: Sage Publications.

Smailes, J. and Gannon-Leary, P. (2011) 'Peer-mentoring: is a virtual form of support a viable alternative?', Research in Learning Technology, 19(2), pp. 129-142.

Smith, T. (ed.) (2013) Undergraduate curricular peer mentoring programs: perspectives on innovation by faculty, staff and students. Maryland: Rowan and Littlefield Publishing Group Inc.

Stake, R. (1995) The art of case study research. London: Sage Publications.

Taber, K. (2013) Classroom-based research and evidence-based practice. $2^{\text {nd }}$ edn. London: Sage Publications. 
Terrion, J. and Leonard, D. (2007) 'A taxonomy of the characteristics of student peer mentors in higher education: findings from a literature review', Mentoring and Tutoring: Partnership in Learning, 15(2), pp. 149-164.

http://dx.doi.org/10.1080/13611260601086311

Thomas, L. (2012) Building student engagement and belonging in higher education at a time of change: final report from the 'What works? Student retention \& success programme'. Available at:

https://www.heacademy.ac.uk/sites/default/files/what works final report.pdf (Accessed: 27 April 2016).

Tinto, V. (1997) 'Classrooms as communities: exploring the educational character of student persistence', Journal of Higher Education, 68(6), pp. 599-623. http://dx.doi.org/10.2307/2959965

Weinberg, F. and Lankau, M. (2010) 'Formal mentoring programmes: a mentor-centric and longitudinal analysis', The Journal of Management, 37(6), pp. 1527-1557. http://dx.doi.org/10.1177/0149206309349310

Wenger, E. (1999) Communities of practice: learning, meaning and identity. Cambridge: Cambridge University Press.

Zier-Vogel, K. and Barry, A. (2013) 'Supporting peer mentors: recruiting, educating and rewarding peer mentors', in Smith, T. (ed.) Undergraduate curricular peer mentoring programs: perspectives on innovation by faculty, staff and students. Maryland: The Rowman and Littlefield Publishing Group Inc., pp. 151-156.

\section{Author details}

Gillian Pye is programme leader for several undergraduate BA Honours degrees and her areas of expertise include pedagogies and mentoring.

Susan Williams is a lecturer on undergraduate professional education programmes in the areas of teaching, learning and peer mentoring. 
Linda Dunne is a lecturer and research fellow. She teaches on undergraduate and postgraduate programmes in education. 